\title{
The Development Process of the Ecological Education in Independent Kazakhstan
}

\author{
Primbetova Aigul ${ }^{1}$ and Baltabayeva Gaukhar ${ }^{2, *}$
}

${ }^{1}$ Korkyt Ata Kyzylorda State University; ${ }^{2}$ Kazakh National Women's Teacher Training University, Kazakhstan

\begin{abstract}
Today, the world community understands that one of the main reasons for the emergence of the global ecological crisis is the low education level, including the ecological one. On the 21st century threshold, the individual's ecological development is becoming a priority and a meaning-forming factor in state education policy. In many ways, it acts not only as a means of preserving nature but also of human civilization as a whole.

This study recommends theorizing and establishing ecological education among learners. The future teacher needs to connect diverse thoughts about ecology and attempt to understand effective practices to cultivate a space of reflection for students and devise effective ways and methodologies to foster ecological education skills thought among student learners.

The purpose of the present study was to collect and analyze environmental education undertaken with various subjects. For systematic analysis, selected databases and journals were analyzed across pre-determined criteria.

The close examination resulted in 11 studies reporting the effects of the interventions (e.g., hands-on practices, field trip activities) and 4 studies reporting participants' views on the effects of the interventions in general. Later, these studies were subjected to content analysis to present the trends and to synthesize the common findings of the selected studies. The techniques and instructions used as the intervention in these selected studies were observed to contribute to the development of participants' gains associated with knowledge of the environment and nature, perception of nature, environmental effect, responsible environment behaviors, and conception and understanding of science.
\end{abstract}

Keywords: Development, process, ecological, education, Independent Kazakhstan.

\section{INTRODUCTION}

The new strategy for the development of civilization is associated with the eco humanitarian paradigm, the humanization of public consciousness, the priority of spiritual values, and an increase in the development of humanity's ecological education of society.

Ecological education, in the narrow sense, is defined as rational nature management. In a broad sense, this concept constitutes a new content of universal human education, based on the priority of universal values - Earth, Nature, Life, Man, Health. Ecological education, manifesting itself in the system of value orientations and motivating ecologically sound behavior, determines the nature and quality level of relations between a person and the socio-natural environment [1].

The specificity of universities in Kazakhstan that incorporate an ecological education consists in following, they implement an ecological module as a mandatory and they included the program of educational work with students which contains a mandatory block "Ecological education of the individual" and involves the student's involvement in

*Address correspondence to this author at the Kazakh State National University of Al-Farabi, Almaty, Kazakhstan; Tel: +77073851878;

E-mail: zhanat_2006@mail.ru ecological activities on practice, by activities like (ecological actions, ecological conferences, ecological festivals, work with schools to promote ecological education); as well as the activities like wide involvement of the pedagogical community and public organizations. Future teachers, participating in activities on ecological education, on the one hand, form personal qualities that manifest ecological education. On the other hand, the future teacher learns the methodological work of organizing and conducting ecological education in practice.

The most important social institution that forms an ecological education and improves its inheritance mechanisms is the system of education for children. Institutions promoting ecology education, integrate basic ecological education and education on speciality, this have a significant potential for the ecological development of an individual, capable of perceiving and implementing in their life the ideas of co-evolution of nature and society, focused on continuous creative self-development, capable of not only adapting to rapidly changing civilization conditions but also providing priority of eco humanistic values in the system "man - society - nature".

When it comes to talking about the importance of environmental education, students often remain confused because they don't actually know how a degree in environmental science can benefit them. If 
you are currently studying biology, chemistry, or another similar subject, you might develop an interest in environmental science in the coming months or weeks. In case you don't know what its core advantages are, this is the right place for you to gain some useful information.

One of the major benefits of environmental education is that it helps kids develop critical thinking skills. This is because they are tasked to do different things daily, weekly, or monthly. If you are a student interested in this field, let us tell you that you will have to complete a couple of projects and eventually boost your critical thinking, learning, and writing capabilities. This will prepare you for a challenging yet prosperous tomorrow.

Research shows that this education is really important. It is not only well-paying but also gives you a sense of responsibility and prepares you to take more care of the people, animals, plants, and other things around you than ever.

As a student, you can learn the value, significance, and importance of STEM. It means you can learn different subjects at a time, such as science, technology, engineering, and mathematics, and can gain more and more skills. This will make you a multiskilled person.

\section{LITERATURE REVIEW}

In the present-day situation, when the number of classes decreases, the most accessible approaches remain the infusion and the modular one. The focus is laid more on the informative character of ecological education during the educational process. To include the messages of the ecological ethics to finalize the ecological education is a means to efficiently make ii more accessible which can be applied from the earliest ages, with a major condition that the educated should have a philosophical culture in this respect.

The recognition of ecological problems humankind has faced refers to the second part of the 20th century, but to this very day, the problems have not been solved. Moreover, they continue to become worse. The development of mankind in the way occurring nowadays leads to the exacerbation of the ecological crisis, which is accomplished by the imbalance between society and nature. Muravjeva considers the low level of a modern technocratic society culture as one of the most important reasons for the ecological crisis. The largest value is thought to be a technological infrastructure compared to harmonic coexistence with nature. The author also believes that the solution of ecological problems is of great importance since these problems affect the bases of civilization processes from which the survival of mankind directly depends on [1].

Environmental education is a conservation strategy that creates such synergistic spaces, facilitating opportunities for scientists, decision-makers, community members, and other stakeholders to converge. Environmental education foregrounds local knowledge, experience, values, and practices, often in place-based settings; in this way, it encourages numerous groups, including those that may be marginalized, to interface productively with research [2]. By definition, environmental education encompasses approaches, tools, and programs that develop and support environmentally related attitudes, values, awareness, knowledge, and skills that prepare people to take informed action on behalf of the environment [3].

It focuses on outcomes at various scales, including at the individual level (e.g., an individual's environmental attitudes or behavior), societal level (e.g., community capacity-building), and ecosystem level (e.g., number of an endangered species). Based on a growing body of research foregrounding behavioral complexity, environmental education has moved away from suggesting a linear path from environmental attitudes to knowledge to action, now emphasizing a dynamic, complex ecosystem of relationships that influence behavior rather than earlier ideas derived from an information-deficit perspective [4].

Despite the achievements of pedagogical science in the development of the methodology and theory of environmental education, as well as the fact that the problem of preparing a teacher for environmental education is currently recognized as relevant, there are very few studies concerning the content and methods of forming the preparedness we have indicated.

The formulation and solution of this problem are associated with the enrichment of education goals, the development of a new methodology, structure, content, technologies, methods, and techniques of teaching and upbringing. The new methodology of an ecological education is largely associated with its humanization and humanitarization, strengthening of the upbringing function, orientation towards the development and selfdevelopment of the individual, the transition from the 
Table 1: The Pedagogical Model of the Formation of the Ecological Education of Future Teachers

\begin{tabular}{|c|c|c|c|}
\hline \multicolumn{4}{|c|}{ target } \\
\hline \multicolumn{2}{|l|}{ goal } & \multicolumn{2}{|c|}{ objectives } \\
\hline \multicolumn{4}{|c|}{ structural and content } \\
\hline methodological approaches & \multicolumn{2}{|c|}{ principles } & pedagogical conditions \\
\hline \multicolumn{4}{|c|}{ technological } \\
\hline methods & \multicolumn{2}{|c|}{ forms } & means \\
\hline \multicolumn{4}{|c|}{ evaluative-criterion-effective } \\
\hline components & criteria & indicators & levels of formation \\
\hline
\end{tabular}

reproductive educational model to the activitytransforming one, from the extensive nature of education to the intensive one [2].

It has already become quite obvious that the ecological education of a society, having exhausted its capabilities, led to the destruction of the fragile balance of the human environment, and unable in some issues to maintain the level of relations necessary to ensure the stability of civilizational development.

Overcoming the current situation is possible under the conditions of the transition to new civilizational models of the formation of relations in the "man-naturesociety" system based on a co-evolutionary strategy that allows achieving synchronous, sustainable development of nature, society, education, and human consciousness. The implementation of a coevolutionary strategy is associated with the formation of civilizational-ecological thinking, which determines the relationship of human society with nature and the surrounding world, based on the ecological imperative's requirements. Fulfillment by each person of imperative ecological prescriptions is possible if the principle of co-evolutionary unity of nature and society is adopted as the meaning-forming basis for building their activities [3].

The ecological education of the future student is presented as an integrative quality of the personality, which manifests its attitude to nature, society, man and oneself through ecological literacy (inclusion in the ecological, political, cultural life of society both independently and through participation in the work of educational and educational organizations, showing ecological knowledge, skills and cognitive activity), ecological upbringing (the aspiration of the individual to develop ecological education, following the law and showing responsibility, kindness and love for nature (the environment, for people and for oneself), ecological awareness (active life position, showing initiative in organizing and conducting socially significant ecological events, self-improvement based on the formation of value orientations and attitudes, motivation, meaning, conviction in the value of nature and in a respectful attitude towards it), ecological activity (focus on participation in socially valuable ecological activities to improve coexistence in the "man-nature" system, showing reflection, proactivity, available arsenal for achieving goals) [4].

The purpose of this research mainly to improve ecological education and give the methodological basis for its enhancement. As it was mentioned before, ecological education implements several tasks as it is very useful to the general knowledge so to the specific aspects as it is improving health, environment, and so on.

\section{METHODS}

The methodology for the formation of the ecological education of future teachers (using the example of universities in Kazakhstan) includes: content (a set of academic disciplines, activities carried out in the process of teaching and upbringing at the university and in the Ecological Center, aimed at the formation of a teacher as a subject of ecological education and upbringing, translating the values of ecological literacy, ecological education, ecological awareness, ecological activity), forms and methods of professional training and education of future teachers, taking into account factors affecting ecological safety, regional features, as well as diagnostic tools, providing control over the development of this process.

In this research, we used different statistical methods for analyzing the process of ecological education, and also we used comparative methods to 
compare the development of the ecological education process in different educational establishments.

Students were provided with some brief online material that gave some details of ecology and was advised to review the previous lecture material before the session. Of the 85 registered students, 50 participated in the activity. Students worked in groups of 4-6 individuals and were provided with a material and a guidance worksheet. After a brief 5-minute introduction where students were given the details of their task and offered the opportunity to ask any questions, they were allotted 40 minutes to undertake the tasks outlined below in a self-guided walk with intermittent supervision. Students were asked to undertake the following tasks:

1) Describe the ecology

2) What evidence for human influence do you observe?

3) What makes this an urban rather than a rural or natural environment?

4) What ecosystems are present?

5) What niches are present?

6) Are there any ecosystems or niches that are novel to this environment?

After the self-guided session, with staff support, students returned to the seminar room for a 20-minute discussion on the walk. Students discussed the ecosystems and niches that they had identified and what key features of the environment were in nature, sharing ideas and photos. A week after the exercise, students were asked to complete a short questionnaire to assess the methodology's perceived usefulness. Answers were given in the form of a five-level scale from 1 . Not at all useful to 5 . Very useful.

\section{RESULTS AND DISCUSSION}

Thirty-two students returned completed questionnaires. The exercise was very well-received, with all students recommended that the activity be run again next year. Over $60 \%$ of students agreed that the activity had helped them better understand some of the key concepts introduced in lectures. Over $50 \%$ agreed that it had helped them develop their understanding of ecology. Simultaneously, in the current traditional system of ecological education, which usually uses the transfer from the educational process of the school not only the content but also the forms, methods, and technologies of working with children, such integration is not possible.

Besides, it should be noted that the ecological development of students in the system of education, despite the ongoing innovative and pedagogical efforts, continues to remain technocratic in nature: the new methodology and philosophy remain largely a declaration, the content of natural science education, as before, is developed within the framework of technocratic approach, forming fragmentary, disparate, often unrelated ideas about the world and not providing the proper conditions for the development of a personality with high ecological education.

Overall, the students enjoyed the activity, and one student commented that there were 'good use of outside space for additional learning.' In addition, students agreed it helped them identify links between the ecosystem and the lectures' theoretical information. Indeed, one student commented that 'learning the

Table 2: Questionnaire and Responses

\begin{tabular}{|c|c|c|c|c|c|c|}
\hline Questions & & 1 & 2 & 3 & 4 & 5 \\
\hline \multirow{2}{*}{$\begin{array}{l}\text { How useful was the pre-activity information in } \\
\text { preparing you for the activity }\end{array}$} & Female & - & - & $32 \%$ & $52 \%$ & - \\
\hline & Male & - & - & $44 \%$ & $38 \%$ & - \\
\hline \multirow{2}{*}{$\begin{array}{l}\text { Rate the usefulness of this activity for developing your understanding of } \\
\qquad \text { ecosystems and ecology }\end{array}$} & Female & - & - & $51 \%$ & $50 \%$ & $5 \%$ \\
\hline & Male & - & - & $26 \%$ & $50 \%$ & - \\
\hline \multirow{2}{*}{$\begin{array}{l}\text { Rate the usefulness of this activity for your understanding of ecological } \\
\text { concepts (e.g., ecosystems, relationships between different organisms }\end{array}$} & Female & - & $8 \%$ & $35 \%$ & $48 \%$ & $23 \%$ \\
\hline & Male & - & $10 \%$ & $19 \%$ & $38 \%$ & $11 \%$ \\
\hline \multirow{2}{*}{$\begin{array}{l}\text { Rate how well you feel this activity complemented } \\
\text { the lecture topics }\end{array}$} & Female & - & $11 \%$ & $29 \%$ & $41 \%$ & $14 \%$ \\
\hline & Male & - & & $26 \%$ & $36 \%$ & - \\
\hline
\end{tabular}


theory behind processes in lectures and then understood them in practice in the lab and field.'

Staff also found that they had a greater opportunity to speak to small groups of students and explain or address the material's misunderstandings. Talking with small groups of students in sessions such as these is likely to have a knock-on effect with students finding staff more approachable and asking more questions in typical teaching sessions. In fact, the module's final session several weeks after this session is a revision session, and the lecturers felt that students were more willing to ask questions this year than previously. This could simply be the cohort in question, but the more informal session may also have helped to make students more comfortable asking questions.

Analysis of the monitoring data of the approbation of regional programs of a new generation in ecological education, the design and creative learning technologies in various types of institutions for the ecological education of learners suggests that their use in the eco humanistic model of ecological education has a positive effect on the development of personality, harmonization of all its spheres, and in general success of the development of ecological education.

An integrative approach based on introducing a culturological component into their content contributes to the development of the emotional-sensory sphere, higher needs (cognitive, aesthetic, self-knowledge, and self-realization) and is a motivator of ecological creative activity and behavior of students in a socio-natural environment [5].

Thanks to the innovative content and design and creative technologies of the educational process, there is a deeper understanding by students of their role and place in the system of the Universe than when using traditional approaches; your attitude to the world around you; intrinsic value, and uniqueness of all living things; the need to comply with moral and ecological imperatives [6].

It is better to mention that there were some works in the ecology education of different scientists in comparison with their research. We paid more attention to the application of ecology education in education process.

The introduction of a humanitarian component into natural science knowledge, an appeal to history, philosophy, art, religion, traditions contribute to the synchronization of the process of teaching and upbringing, which contributes to the formation of students' own system of values and motives for creative ecological activity. This tendency has a formative effect on the formation of such personality traits as humanity, mercy, responsiveness, frugality, responsibility, activity, citizenship, education of communication and behavior, etc.

The effectiveness of the influence of the content of ecological education on students' ecological education indicators significantly increases if it is supported by design and constructive technologies focused on the harmonious development of the student and his practical activities in the socio-natural environment [7].

The combination of the content of ecological education and the corresponding innovative teaching technologies makes the learning process interesting and personally significant for the student. This condition has a huge impact on the development of all basic indicators of the individual's ecological education and the formation of an eco humanistic worldview [8].

We can consider that the programs and innovative technologies developed by us are an important means of developing students' ecological education. Under the conditions of their development in the eco humanistic model of ecological education, the formation of diagnosed indicators is more efficient than under the conditions of traditional programs and ecological education technologies for children [9].

The results of monitoring provide convincing evidence of this statement.

The content of ecological education, which has developed within the technocratic paradigm framework, needs a conceptual restructuring in modern sociocultural conditions. It is quite relevant to study the problems of educational and methodological support of ecological education for children, the specifics of training education teachers that meet the requirements of the eco humanistic imperative [10].

There is a need for the formation of a new field of scientific knowledge - "pedagogical ecology", coordinating pedagogical research in the plane of solving the problems of meaningful renewal of ecological education, identifying the role of nature in spiritual enrichment and moral and ethical development of the individual in conditions of ecologization of the life of society [11].

Ecological education from the designated positions acts as a new content of the third millennium's 
universal human education, which is based on humanistic orientations and universal values. Humanistic orientations in the context of the actualization of ecocentric intentions determine the common interests of man and nature as equal partners of co-evolutionary development and are defined in the study as eco humanistic [12].

The structure of the ecological education of the individual includes: an eco humanistic worldview (the core of ecological education); personal experience of interaction with the outside world; ecological knowledge, skills, and abilities, which together form a holistic nature-oriented picture of the world and determine the creative nature of the ecological activity of students (the ability to model ecological situations and predict their development, the ability to make ecologically responsible decisions), Mastering eco humanistic knowledge in the conditions of application of design-creative pedagogical technologies actualizes the perceiving capabilities and cognitive abilities of students, thanks to which natural curiosity develops faster than usual into a sustainable interest, motives and needs for ecologically sound activities [13].

Ecology of Education is one of the trends of human ecology with its own history. As an interdisciplinary trend of research, educational ecology offers a wide range of research opportunities in the field of education. There exist the following conceptual approaches of research in the field of educational ecology: the interdisciplinary approach, the ecological approach, the humanistic approach, which complementary supplement each other, ensuring the holistic approach, first of all, systems approach, in the educational research [14].

\section{CONCLUSION}

Ecology of Education as a research trend has a scientifically substantiated philosophicalmethodological basis. It is important in the educational research to move from the ecological paradigm to the modern educational process and research practice, the substantiation of which would be based on scientific conceptions, theories, as well as the environmental models developed by scientists.

It is essential to base the development of environmental models on the systems approach, showing respect to the environmental taxonomy principle, as well as the classifications of environmental components/contexts.
Ecology of Education offers several research perspectives, the substantiation of which we can find in the two main trends:

1) Ecology of human development;

2) Ecology of systems development. One of the research perspectives is related to studies of sustainable development.

The research performed in the field of environmental education also has a significant place within the educational ecology.

This research work proved its necessity by the urgency of this problem nowadays. This research proved once more that our learners need at present to have ecology education.

But still, for future research, we made a way, and in the next research work, we will pay more attention to the ecology teachers' training. So this is a suggestion for a future experiment.

\section{ACKNOWLEDGEMENT}

None.

\section{REFERENCES}

[1] Muravjeva EV. Ecological education of technical students as a basic constituent of the strategy for ecological crisis overcoming. Synopsis of the Doctoral thesis, Kazan 2008.

[2] Toomey AH, Knight AT, Barlow J. Navigating the space between research and implementation in conservation. Conserv Lett 2017; 10: 619-625. https://doi.org/10.1111/conl.12315

[3] Krasny M. A response to Scott's concerns about the relevance of environmental education research: applying social-ecological systems thinking and consilience to defining research goals. Environ Educ Res 2009; 15: 189-198. https://doi.org/10.1080/13504620902770352

[4] Marcinkowski T, Reid A. Reviews of research on the attitudebehavior relationship and their implications for future environmental education research. Environ Educ Res 2019; 25: 459-471. https://doi.org/10.1080/13504622.2019.1634237

[5] Cornell J. Listening to Nature Now to Deepen Your Awareness of Nature. NC, 1987; p. 95.

[6] Hutchins E. Cognition in the Wild. Cambridge (Mass): MIT Press 1995; p. 354.

https://doi.org/10.7551/mitpress/1881.001.0001

[7] Kohlberg L. The development of Children's Orientations towards a moral Order. Chicago 1963.

[8] Simon SB, Kirshenbaum HN. Values, and Future Education Moment. Learning for Tomorrow. NY 1974.

[9] Ward Leo R. Philosophy of Education. Chicago 1963.

[10] Weinberg C. Humanistic Foundation of Education. NY 1972.

[11] Urlich Roger S. Biophilia, biophobia, and natural landscapes. -USA: Texas 1993; p. 66. 
[12] Maslow AH. The Farther Reaches of Human Nature.- NY 1971; p. 409.
[13] Perry RB. General Theory of Value. Cambridge 1950.

[14] Mead GH. Mind, self, and society. Chicago 1934.

Received on 04-08-2020

Published on 14-09-2020

DOI: https://doi.org/10.6000/2292-2598.2020.08.03.35

(C) 2020 Aigul and Gaukhar; Licensee Lifescience Global.

This is an open access article licensed under the terms of the Creative Commons Attribution Non-Commercial License (http://creativecommons.org/licenses/by-nc/3.0/) which permits unrestricted, non-commercial use, distribution and reproduction in any medium, provided the work is properly cited. 